\title{
Long-term Survival of Stage IV Melanoma Patients Treated with BOLD Combination Chemotherapy and Intermediate-dose Subcutaneous Interferon-alpha
}

\author{
KALLE MATTILA $^{1}$, PIRITA RAANTA ${ }^{1}$, VALTTERI LAHTELA ${ }^{1}$, \\ SEPPO PYRHÖNEN ${ }^{1}$, ILKKA KOSKIVUO $^{2}$ and PIA VIHINEN ${ }^{1}$ \\ ${ }^{1}$ Department of Oncology and Radiotherapy, and ${ }^{2}$ Plastic Surgery, \\ University of Turku and Turku University Hospital and FICAN West Cancer Centre, Turku, Finland
}

\begin{abstract}
Background: Immune checkpoint and serine/ threonine-protein kinase inhibitors have become a standard of care for advanced cutaneous melanoma, but dacarbazinebased chemotherapies are occasionally used. This study assessed the long-term efficacy of chemoimmunotherapy (bleomycin, vincristine, lomustine and dacarbazine with/ without subcutaneous interferon-alpha: BOLD-INF- $\alpha$ ) as realworld data in patients with metastatic melanoma not eligible for clinical trials. Patients and Methods: Medical data of 146 patients with stage IV melanoma who had received BOLD/BOLD-INFa regimen during 1991-2010 were analyzed. Results: The median overall survival was 8.9 months $(95 \%$ confidence intervaI=7.5-10.4 months). The 1-year survival rate was $36 \%$, 2-year 18\%, and 5-year 13\%. The 5-year survival rates in the M1a, M1b and M1c subgroups were $28 \%, 10 \%$ and $6 \%$, respectively. Overall, $7 \%(n=11)$ of the patients were alive at the end of the follow-up. Conclusion: Our study showed similar overall survival among patients with stage IV cutaneous melanoma treated with BOLD/BOLD-INF $\alpha$ as noted previously with chemotherapy.
\end{abstract}

The treatment of advanced melanoma is evolving rapidly. Dacarbazine or temozolomide were the standard of treatment before the development of immune checkpoint inhibitors, anti-cytotoxic T-lymphocyte-associated protein 4 (CTLA4) agent ipilimumab $(1,2)$ and anti-programmed cell death protein 1 (PD1) agent nivolumab $(2,3)$ and pembrolizumab $(2,4)$, as well as the $\mathrm{v}$-Raf murine sarcoma viral oncogene

Correspondence to: Kalle Mattila, MD, Department of Oncology and Radiotherapy, Turku University Hospital, POB 52, FIN-20521 Turku, Finland. Tel: +358 23130000, Fax: +358 3132809, e-mail: kalle.mattila@tyks.fi

Key Words: Melanoma, metastasis, chemotherapy, survival, realworld data. homolog B (BRAF) inhibitors vemurafenib $(2,5)$, dabrafenib $(2,6)$ and trametinib (6). Single-agent dacarbazine was associated with an objective response rate (ORR) of $13 \%$ and the median overall survival (OS) of 8.9 months (range $=5.6-$ 11 months) (6). A previous meta-analysis showed that combination of dacarbazine with older immunotherapies, i.e. interferon-alpha (INF $\alpha)$ or interleukins, increased ORR to $21.5 \%$ (7). Combination chemotherapy with bleomycin, vincristine, lomustine and dacarbazine (BOLD) and INF $\alpha$ increased the ORR even up to $62 \%$ with $13 \%$ complete responses (CR) and 49\% partial responses (PR), as reported in a phase II clinical trial (8). Another phase II clinical trial showed six CRs among patients with stage 4 melanoma with soft-tissue and lung metastases treated with BOLD-INF $\alpha$ (9).

Although BOLD-INF $\alpha$ was shown to lead to a higher ORR compared to single-agent dacarbazine, it failed to prolong OS (9-12). In a Finnish four-armed, randomized, phase II clinical trial, single-agent dacarbazine, or BOLD were combined with natural or recombinant INF $\alpha$ in the treatment of patients with advanced cutaneous melanoma. Tumor responses tended to be higher with BOLD combined with recombinant INF $\alpha$, but there was no significant difference in OS between the different treatment arms. The median OS in that study was 9.0 months and $7 \%$ of the patients survived over 5 years (9). Other combination chemotherapy regimens such as cisplatin with vinblastine and dacarbazine (CVD), Dartmouth Regimen (dacarbazine, carmustine, cisplatin, tamoxifen) and carboplatin with paclitaxel have also been used in the treatment of advanced melanoma, with similar OS results $(6,10,12)$.

The 5-year survival rate among patients with stage 4 melanoma treated with dacarbazine is low, ranging from $6-9 \%(10,13)$. In a recent analysis of treatment-naïve patients with advanced melanoma who had received ipilimumab plus dacarbazine or dacarbazine alone, the survival rate of the dacarbazine-treated arm was $36 \%$ at 1 year, $18 \%$ at 2 years, $12 \%$ at 3 years and $9 \%$ at 5 years (13). A 5-year survival rate of $10 \%$ was also recorded in patients 
with metastatic melanoma treated with BOLD-INF $\alpha$ chemoimmunotherapy (14). The aim of our study was to analyze the long-term survival of patients with stage IV cutaneous or unknown primary melanoma treated with BOLD/BOLD-INF $\alpha$ in a retrospective real-world evidence patient population treated outside clinical trials before acceptance of modern therapies and to analyze prognostic factors for survival.

\section{Patients and Methods}

Patients. The study population consisted of patients with metastatic cutaneous or unknown primary melanoma considered eligible for combination chemotherapy at the Department of Oncology and Radiotherapy at Turku University Hospital, Finland, during 19912010. Patients were not eligible for surgery or radiotherapy alone, nor for any clinical trial. All patients received at least one cycle of BOLD with or without subcutaneous INF $\alpha$ during the course of their disease. This time period was selected because new immunotherapies or BRAF inhibitors were not available outside clinical trials until 2010. Patients were followed-up until March 30th, 2016. The median duration of follow-up was 8.9 months (range=0 $8-224,5$ months).

During 1991-2010, altogether 153 patients received BOLD/BOLDINF $\alpha$ for the treatment of stage IV melanoma. Five patients were excluded due to missing follow-up data and one patient with uveal and one patient with gastrointestinal primary melanoma were excluded. Thus, a total of 146 patients were included in this analysis. The study cohort represented a real-life patient population with stage IV melanoma eligible for chemotherapy attending our clinic.

Study design. This study was a retrospective cohort study. Survival data were obtained from Statistics Finland. Medical histories of study patients were gathered from Turku University Hospital patient records. The primary objective of our study was to assess the longterm survival of patients with stage IV melanoma treated with BOLD/BOLD-INF $\alpha$ before modern therapies were available. Secondary objectives were to analyze progression-free survival (PFS), ORR, safety of BOLD/BOLD-INF $\alpha$ regimens and prognostic factors for survival.

Treatment. The BOLD-INF $\alpha$ regimen comprised $15 \mathrm{mg}$ bleomycin intravenously (i.v.) on days 2 and $5,1 \mathrm{mg} / \mathrm{m}^{2}$ vincristine $i . v$. to a maximum of $2 \mathrm{mg}$ on days 1 and $4,80 \mathrm{mg}$ lomustine orally on day 1 and $200 \mathrm{mg} / \mathrm{m}^{2}$ dacarbazine i.v. on days $1-5$. One cycle lasted for 28 days. INF $\alpha$ was administered subcutaneously at 3 MIU daily starting on day 8 for 6 weeks and 6 MIU three times per week thereafter. The treatment was continued until unacceptable toxicity, deterioration of patient`s performance status or disease progression (PD) (15).

Statistical analysis. Statistical analyses were performed using IBM SPSS Statistics 21 (IBM, Armonk, NY, USA). Effect measures are presented with $95 \%$ confidence intervals (CI). Kaplan-Meier curves were prepared to analyze the OS and the PFS. Differences in OS between the subgroups were analyzed pairwise. OS was calculated from the beginning of the BOLD/BOLD-INF $\alpha$ treatment to death or the last day of follow-up. PFS was calculated from the beginning of the BOLD/BOLD-INF $\alpha$ treatment to computed tomographic scandetected disease progression or to the beginning of best supportive care. Investigator-assessed RECIST 1.1. criteria (15) were used for the treatment response analysis. The Cox regression method was used to analyze the association of prognostic factors with death.

\section{Results}

Patients and treatment. A total of 146 patients received at least one dose of BOLD/BOLD-INF $\alpha$. The median number of BOLD/BOLD-INF $\alpha$ cycles was 4 (range=1-13); 62\% ( $=91)$ received 1-4 cycles and $38 \% \quad(n=55)$ 5-13 cycles of BOLD/BOLD-INF $\alpha$. Ninety-two percent $(n=134)$ of the patients received BOLD with subcutaneous INF $\alpha$, and only $8 \%$ $(n=12)$ received BOLD alone. Receipt of oncologicaI therapy before and after BOLD/BOLD-INF $\alpha$ varied markedly. Adjuvant INF $\alpha(n=12,8 \%)$, dacarbazine-INF $\alpha(n=3,2 \%)$ and isolated limb perfusion $(n=3,2 \%)$ were the most common therapies before BOLD/BOLD-INF $\alpha$. Cisplatin-etoposide or carboplatinetoposide $(\mathrm{n}=28,19 \%)$, alkylating chemo-therapeutic agents (temozolomide, dacarbazine or BOLD re-challenge) $(n=26$, $18 \%)$ and subcutaneous INF $\alpha$ maintenance therapy $(n=24,16 \%)$ were the most common subsequent therapies. Fifty-seven percent $(n=83)$ of the patients had received radiotherapy and $56 \%(n=82)$ had undergone operative treatment of metastases. Characteristics of the study population are summarized in Table I.

Efficacy and safety. The median PFS of patients treated with BOLD/BOLD-INF $\alpha$ therapy was 3.8 months (95\% CI=3.0-4.6 months). The investigator-assessed ORR was $29 \%(n=43)$. Partial response (PR) was achieved in $23 \%(n=33)$ and complete response $(\mathrm{CR})$ in $7 \%(\mathrm{n}=10)$ of the patients, while $24 \%(n=35)$ of the patients achieved stable disease (SD); PD was found in $46 \%(n=68)$ of the patients. The most common causes for the termination of BOLD/BOLD-INF $\alpha$ therapy were PD in $61 \%(n=89)$ of the patients, adverse events (AE) in $12 \%(n=18)$ of the patients, and planned termination after six or eight cycles of BOLD in $12 \%(n=18)$ of the patients. The most common AEs were fatigue in $38 \%(n=56)$, hematological (anemia, neutropenia, thrombo-cytopenia) in $23 \%(\mathrm{n}=34)$ and peripheral neuropathy in $23 \%(n=34)$. There were 15 cases of pulmonary reactions probably related to bleomycin. The incidence of AEs may have been underestimated because of the lack of systematic reporting of AEs outside of clinical trials.

Overall survival. A total of 135 deaths had occurred by the end of the follow-up. Two causes of deaths were not melanoma related, one being heart failure and the other being hemorrhagic gastritis. The median OS was 8.9 months (95\% CI=7.5-10.4 months). The 1-, 2-and 5-year survival rates were $36 \%(n=53), 18 \%(n=27)$ and $13 \%(n=19)$, respectively. Seven percent $(n=11)$ of the patients were alive at the end of the follow-up. The characteristics of 5-year survivors are summarized in Table II.

The M-stage according to American Joint Committee on Cancer 7th edition (16) was significantly associated with OS1 
Table I. Characteristics of 146 patients with stage IV melanoma.

\begin{tabular}{|c|c|}
\hline Characteristic & Value \\
\hline \multicolumn{2}{|l|}{ Age, years } \\
\hline Median (range) & $58(21-79)$ \\
\hline Male & $97(66 \%)$ \\
\hline Female & $49(34 \%)$ \\
\hline \multicolumn{2}{|c|}{ Charlson comorbidity index } \\
\hline Median (range) & $6(6-12)$ \\
\hline \multicolumn{2}{|l|}{ ECOG PS } \\
\hline 0 & $22(15 \%)$ \\
\hline 1 & $82(56 \%)$ \\
\hline $2-3$ & $19(13 \%)$ \\
\hline Unknown & $23(16 \%)$ \\
\hline \multicolumn{2}{|l|}{ Primary melanoma } \\
\hline Cutaneous & $128(88 \%)$ \\
\hline Unknown & $18(12 \%)$ \\
\hline \multicolumn{2}{|l|}{ M-Stage* } \\
\hline M1a & $39(27 \%)$ \\
\hline M1b & $39(27 \%)$ \\
\hline M1c & $68(46 \%)$ \\
\hline \multicolumn{2}{|l|}{ Treatment } \\
\hline BOLD-INF $\alpha$ & $134(92 \%)$ \\
\hline BOLD & $12(8 \%)$ \\
\hline \multicolumn{2}{|c|}{ Number of cycles of BOLD/BOLD-INF $\alpha$} \\
\hline Median (range) & $4(1-13)$ \\
\hline \multicolumn{2}{|c|}{ Oncological therapy before BOLD/BOLD-INF $\alpha$} \\
\hline Yes & $24(16 \%)$ \\
\hline No & $122(84 \%)$ \\
\hline \multicolumn{2}{|c|}{ Oncological therapy after BOLD/BOLD-INF $\alpha$} \\
\hline Yes & $71(49 \%)$ \\
\hline No & $72(49 \%)$ \\
\hline Unknown & $3(2 \%)$ \\
\hline \multicolumn{2}{|c|}{ Radiotherapy of metastases } \\
\hline Yes & $83(57 \%)$ \\
\hline No & $62(42 \%)$ \\
\hline Unknown & $1(1 \%)$ \\
\hline \multicolumn{2}{|c|}{ Surgery of metastases } \\
\hline Yes & $82(56 \%)$ \\
\hline No & $64(44 \%)$ \\
\hline
\end{tabular}

ECOG PS: Eastern Cooperative Oncology Group performance status; BOLD: bleomycin, vincristine, lomustine and dacarbazine; INF $\alpha$ : interferon-alpha; M-stage: metastasis stage. *According to American Joint Committee on Cancer 7th edition (16).

$(p=0.001)$ in the Kaplan-Meier (log-rank) analysis. In pairwise comparisons, the survival of the M1a was significantly better than that of the M1c subgroup $(p<0.001)$ as was that of the M1b subgroup $(p=0.041)$. The survival rates are presented in Table III.

Prognostic factors. A Cox regression analysis was performed to analyze the prognostic factors of death in the study cohort. Variables in the analysis consisted of gender (male/female), site of primary melanoma (cutaneous/unknown primary), age at the beginning of BOLD/BOLD-INF $\alpha$ (years), Charlson comorbidity index (17), Eastern Cooperative Oncology
Table II. Characteristics of 19 patients with stage IV melanoma surviving 5 years.

\begin{tabular}{lr}
\hline Characteristic & Value \\
\hline Age, years & \\
$\quad$ Median (range) & $59(40-79)$ \\
Gender, n (\%) & $7(37 \%)$ \\
$\quad$ Male & $12(63 \%)$ \\
Female & \\
ECOG PS, n (\%) & $7(37 \%)$ \\
0 & $10(53 \%)$ \\
1 & $2(10 \%)$ \\
Unknown & \\
M-Stage, n (\%) & $11(58 \%)$ \\
M1a & $4(21 \%)$ \\
M1b & $4(21 \%)$ \\
M1c & \\
Number of cycles BOLD/BOLD-INF $\alpha, n(\%)$ & $5(1-10)$ \\
Median (range) & $5(26 \%)$ \\
Oncological therapy before BOLD/BOLD-INF $\alpha, n(\%)$ & $14(74 \%)$ \\
Yes & \\
No & $11(58 \%)$ \\
Oncological therapy after BOLD/BOLD-INF $\alpha, n(\%)$ & $8(42 \%)$ \\
Yes & $16(84 \%)$ \\
No & $3(16 \%)$ \\
Surgical therapy of metastases, n (\%) & $12(63 \%)$ \\
Yes & $7(37 \%)$ \\
No & \\
Radiotherapy of metastases, n (\%) & \\
Yes & \\
No & \\
\hline
\end{tabular}

ECOG PS: Eastern Cooperative Oncology Group performance status; BOLD: bleomycin, vincristine, lomustine and dacarbazine; INF $\alpha$ : interferon-alpha; M-stage: metastasis stage. *According to American Joint Committee on Cancer 7th edition (16).

Group (ECOG) performance status (0/1/2/3), M-stage (M1a/M1b/M1c), regimen (BOLD/BOLD-INF $\alpha$ ), number of BOLD/BOLD-INF $\alpha$ cycles $(n=1-4 / n=5-13)$, radiotherapy of metastases (yes/no), surgical therapy of metastases (yes/no), oncologic therapy before BOLD/BOLD-INF $\alpha$ (yes/no) and oncologic therapy after BOLD/BOLD-INF $\alpha$ (yes/no).

Fewer BOLD/BOLD-INF $\alpha$ cycles $(p<0.001)$, poorer baseline ECOG performance status $(p=0.001)$, male gender $(p=0.001)$, absence of chemotherapy after BOLD/BOLD-INF $\alpha$ $(p=0.006)$ and more advanced M-stage $(p=0.012)$ were adverse prognostic factors in the multivariate analysis. The hazard ratio (HR) of death was 3.4 (95\% CI=2.1-5.4) among patients who had received 1-4 BOLD/BOLD-INF $\alpha$ cycles compared to those who had received 5-13 BOLD/BOLD-INF $\alpha$ cycles. The HR of death was $1.9(95 \% \mathrm{CI}=1.3-2.8)$ following each decline in baseline ECOG performance status. The HR for death of men was $2.1(95 \% \mathrm{CI}=1.3-3.4)$ compared to women. The HR of death was 1.9 (95\% $\mathrm{CI}=1.2-3-0)$ for those who did not receive chemotherapy after BOLD/BOLD-INF $\alpha$ and 1.4 (95\% CI=1.11.9) for each advance in M-stage. 
Table III. Survival rates and median overall survival OS) of study patients according to M-stage (16).

\begin{tabular}{lcccc}
\hline & \multicolumn{3}{c}{ Survival rate } & \\
\cline { 2 - 4 } Subgroup & 1-Year & 2-Year & 5-Year & $\begin{array}{c}\text { Median OS (95\% CI), } \\
\text { months }\end{array}$ \\
\hline M1a (n=39) & $51 \%$ & $38 \%$ & $28 \%$ & $12.7(8.7-16.6)$ \\
M1b (n=39) & $38 \%$ & $13 \%$ & $10 \%$ & $10.3(7.9-12.6)$ \\
M1c (n=68) & $26 \%$ & $10 \%$ & $6 \%$ & $6.4(4.7-8.2)$ \\
Total $(\mathrm{n}=146)$ & $36 \%$ & $18 \%$ & $13 \%$ & $8.9(7.5-10.4)$ \\
\hline
\end{tabular}

CI: Confidence intervaI.

\section{Discussion}

Our retrospective study demonstrated similar efficacy and longterm survival rate with BOLD/BOLD-INF $\alpha$ in patients with stage IV melanoma treated outside clinical trials, as noted in previous clinical trials with dacarbazine-based chemotherapy $(2,9,12,13)$. The 5 -year survival rate of $13 \%$ in this cohort was relatively high and $7 \%$ of patients were still alive at the end of the follow-up, representing long-term survivors. Treatment was feasible and was discontinued in only $12 \%$ because of AEs. At 29\%, the ORR with BOLD/BOLD-INF $\alpha$ was higher than that achieved with single-agent dacarbazine with/without INF $\alpha$ in clinical trials $(6,7)$.

We analyzed clinical factors which might be associated with better survival. Fewer BOLD/BOLD-INF $\alpha$ cycles was associated with shorter survival. The number of BOLD/BOLD-INF $\alpha$ cycles was also correlated to the response to therapy. The first response evaluation with computed tomographic scan was usually taken after three cycles of BOLD/BOLD-INF $\alpha$ and patients with PD were subjected to another therapy or palliative care. Subsequent therapies were associated with better survival, which is probably related to the effect of these therapies on survival and the ability to give subsequent therapies to patients with favorable response to BOLD/BOLD-INF $\alpha$. AJCC M-stage was associated with better survival in the Kaplan-Meier analysis and in the multivariate analysis. For the M1a subgroup, the plateau in the survival curve was reached at a survival rate of $18 \%$. Lower tumor burden and better performance status have also been suggested to predict better prognosis with immunotherapies (2).

Limitations of this study include its retrospective design, lack of a control group and a small number of patients. During 1991-2010, BOLD/BOLD-INF $\alpha$ was the standard first-line treatment option for stage IV melanoma at our clinic and our study cohort represents a typical real-life population of patients with stage IV melanoma eligible for chemotherapy. Our findings were consistent in terms of OS and long-term survival with earlier studies of BOLD-INF $\alpha$ chemoimmunotherapy $(8,9,14)$.
Immune checkpoint inhibitors and BRAF and mitogenactivated protein kinase (MEK) inhibitors have replaced chemotherapy in the first-line therapy option for stage IV melanoma (2). A pooled analysis of the long-term OS data from phase II and III clinical trials with ipilimumab in advanced melanoma showed a median OS of 11.4 months and 3-year median OS of $22 \%$ (18). The median OS of stage IV melanoma is being further extended in current clinical trials with anti-PD1 agents nivolumab and pembrolizumab $(19,20)$, combination immunotherapy with anti-CTLA4 agent ipilimumab plus nivolumab (21), as well as with the combination of BRAF and MEK inhibitors vemurafenib and cobimetinib (22), and dabrafenib and trametinib $(23,24)$. Unfortunately, the majority of patients still develop PD during novel therapies and subsequent treatment options are needed. In addition, patients with wild-type $B R A F$ gene and poor performance status $(>1)$, high serum lactate dehydrogenase (more than twice normal upper level), or with symptomatic brain metastases have only very limited treatment options. We conclude that traditional dacarbazine-based chemoimmunotherapy may still be a feasible treatment option for patients with stage IV melanoma not suitable for modern therapies.

\section{Conflicts of Interest}

The Authors declare that there is no conflict of interests in regard to this study.

\section{Acknowledgements}

The writing phase of this article was partly funded by the research grant from the Turku University Hospital, Finland.

\section{References}

1 Hodi FS, O'Day SJ, McDermott DF, Weber RW, Sosman JA, Haanen JB, Gonzalez R, Robert C, Schadendorf D, Hassel JC, Akerley W, van den Eertwegh AJ, Lutzky J, Lorigan P, Vaubel JM, Linette GP, Hogg D, Ottensmeier CH, Lebbé C, Peschel C, Quirt I, Clark JI, Wolchok JD, Weber JS, Tian J, Yellin MJ, Nichol GM, Hoos A and Urba WJ: Improved survival with ipilimumab in patients with metastatic melanoma. N Engl J Med 363: 711-723, 2010.

2 Schaderdorf D, van Akkooi ACJ, Berking C, Griewank KG, Hauschild A, Stang A, Roesch A and Ugurel S: Melanoma. Lancet 15: 971-984, 2018.

3 Robert C, Long GV, Brady B, Dutriaux C, Maio M, Mortier L, Hassel JC, Rutkowski P, McNeil C, Kalinka-Warzocha E, Savage KJ, Hernberg MM, Lebbé C, Charles J, Mihalcioiu C, Chiarion-Sileni V, Mauch C, Cognetti F, Arance A, Schmidt H, Schadendorf D, Gogas H, Lundgren-Eriksson L, Horak C, Sharkey B, Waxman IM, Atkinson V and Ascierto PA: Nivolumab in previously untreated melanoma without $B R A F$ mutation. N Engl J Med 372: 320-330, 2015.

4 Robert C, Schachter J, Long GV, Arance A, Grob JJ, Mortier L, Daud A, Carlino MS, McNeil C, Lotem M, Larkin J, Lorigan P, Neyns B, Blank CU, Hamid O, Mateus C, Shapira-Frommer R, 
Kosh M, Zhou H, Ibrahim N, Ebbinghaus S, Ribas A; KEYNOTE-006 investigators: Pembrolizumab versus Ipilimumab in advanced melanoma. N Engl J Med 372: 2521-2532, 2015.

5 Chapman PB, Hauschild A, Robert C, Haanen JB, Ascierto P, Larkin J, Dummer R, Garbe C, Testori A, Maio M, Hogg D, Lorigan P, Lebbe C, Jouary T, Schadendorf D, Ribas A, O’Day SJ, Sosman JA; Kirkwood JM, Eggermont AM, Dreno B, Nolop K, Li J, Nelson B, Hou J, Lee RJ, Flaherty KT, McArthur GA; BRIM-3 Study Group: Improved survival with vemurafenib in melanoma with BRAF V600E mutation. N Eng J Med 364: 2507-2516, 2011.

6 Hauschild A, Grob JJ, Demidov LV, Jouary T, Gutzmer R, Millward M, Rutkowski P, Blank CU, Miller WH Jr., Kaempgen E, Martin-Algarra S, Karaszewska B, Mauch C, Chiarion-Sileni V, Martin AM, Swann S, Haney P, Mirakhur B, Guckert ME, Goodman V and Chapman PB: Dabrafenib in BRAF-mutated metastatic melanoma: A multicentre, open-label, phase 3 randomised controlled trial. Lancet 380: 358-365, 2012.

7 Yang AS and Chapman PB: The history and future of chemotherapy for melanoma. Hematol Oncol Clin North Am 23: 583-597, 2009.

8 Huncharek M, Caubet JF and McGarry R: Single-agent dacarbazine versus combination chemotherapy with or without immunotherapy in metastatic melanoma: a meta-analysis of 3273 patients from 20 randomized trials. Melanoma Res 11: 75-81, 2001.

9 Pyrhönen S, Hahka-Kemppinen M and Muhonen T: A promising interferon plus four-drug chemotherapy regimen for metastatic melanoma. J Clin Oncol 10: 1919-1926, 1992.

10 Vuoristo MS, Hahka-Kemppinen M, Parvinen LM, Pyrhönen S, Seppä H, Korpela M and Kellokumpu-Lehtinen P: Randomized trial of dacarbazine versus bleomycin, vincristine, lomustine and dacarbazine (BOLD) chemotherapy combined with natural or recombinant interferon-alpha in patients with advanced melanoma. Melanoma Res 15: 291-296, 2005.

11 Ugurel S, Röhmel J, Ascierto PA, Flaherty KT, Grob JJ, Hauschild A, Larkin J, Long GV, Lorigan P, McArthur GA; Ribas A, Robert C, Schadendorf D and Garbe C: Survival of patients with advanced metastatic melanoma: The impact of novel therapies. Eur J Cancer 53: 125-134, 2016.

12 Garbe C, Eigentler TK, Keilholz U, Hauschild A and Kirkwood JM: Systematic review of medical treatment in melanoma: Current status and future prospects. Oncologist 16: 5-24, 2011.

13 Eigentler TK, Caroli UM, Radny P and Garbe C: Palliative therapy of disseminated malignant melanoma: A systematic review of 41 randomised clinical trials. Lancet Onc 4: 748-759, 2003.

14 Maio M, Grob JJ, Aamdal S, Bondarenko I, Robert C, Thomas L, Garbe C, Chiarion-Sileni V, Testori A, Chen TT, Tschaika M and Wolchok JD: Five-year survival rates for treatment-naive patients with advanced melanoma who received ipilimumab plus dacarbazine in a phase III trial. J Clin Oncol 33: 1191-1196, 2015.

15 Eisenhauer EA, Therasse P, Bogaerts J, Schwartz LH, Sargent D, Ford R, Dancey J, Arbuck S, Gwyther S, Mooney M, Rubinstein L, Shankar L, Dodd L, Kaplan R, Lacombe D and Verweij J: New response evaluation criteria in solid tumours: Revised RECIST guideline (version 1.1) Eur J Cancer 45: 228247, 2009.

16 Edge SB and Complan CC: The American Joint committee on cancer: The 7th edition of the AJCC cancer staging manual and the future TNM. Ann Surg Oncol 17: 1471-1474, 2010.

17 Charlson ME, Pompei P, Ales KL and MacKenzie CR: A new method of classifying prognostic comorbidity in longitudinal studies: Development and validation. J Chronic Dis 40: 373-383, 1987.

18 Schadendorf D, Hodi FS, Robert C, Weber JS, Margolin K, Hamid O, Patt D, Chen TT, Berman DM and Wolchok JD: Pooled analysis of long-term survival data from phase II and phase III trials of ipilimumab in unresectable or metastatic melanoma. J Clin Oncol 33: 1889-1894, 2015.

19 Topalian SL, Sznol M, McDermott DF, Kluger HM; Carvajal RD, Sharfman WH, Brahmer JR, Lawrence DP, Atkins MB, Powderly JD, Leming PD, Lipson EJ, Puzanov I, Smith DC, Taube JM, Wigginton JM, Kollia GD, Gupta A, Pardoll DM, Sosman JA and Hodi FS: Survival, durable tumor remission, and long-term safety in patients with advanced melanoma receiving nivolumab. J Clin Oncol 32: 1020-1030, 2014.

20 Ribas A, Hamid O, Daud A, Hodi FS, Wolchok JD, Kefford R, Joshua AM, Patnaik A, Hwu WJ, Weber JS, Gangadhar TC, Hersey P, Dronca R, Joseph RW, Zarour H, Chmielowski B, Lawrence DP, Algazi A, Rizvi NA, Hoffner B, Mateus C, Gergich K, Lindia JA, Giannotti M, Li XN, Ebbinghaus S, Kang SP and Robert C: Association of pembrolizumab with tumor response and survival among patients with advanced melanoma. JAMA 315: 1600-1609, 2016.

21 Hodi FS, Chesney J, Pavlick AC, Robert C, Grossmann KF, McDermott DF, Linette GP, Meyer N, Giguere JK; Agarwala SS, Shaheen M, Ernstoff MS, Minor DR, Salama AK; Taylor MH, Ott PA; Horak C, Gagnier P, Jiang J, Wolchok JD and Postow MA: Combined nivolumab and ipilimumab versus ipilimumab alone in patients with advanced melanoma: 2-year overall survival outcomes in a multicentre, randomised, controlled, phase 2 trial. Lancet Oncol 17: 1558-1568, 2016.

22 Ascierto PA, McArthur GA, Dréno B, Atkinson V, Liszkay G, Di Giacomo AM, Mandala M, Demidov L, Stroyakovskiy D, Thomas L, de la Cruz-Merino L, Dutriaux C, Garbe C, Yan Y, Wongchenko M, Chang I, Hsu JJ, Koralek DO, Rooney I, Robas $\mathrm{A}$ and Larkin J: Cobimetinib combined with vemurafenib in advanced $B R A F(\mathrm{~V} 600)$-mutant melanoma (coBRIM): updated efficacy results from a randomised, double-blind, phase 3 trial. Lancet Oncol 17: 1248-1260, 2016.

23 Long GV, Stroyakovskiy D, Gogas H, Levchenko E, de Braud F, Larkin J, Garbe C, Jouary T, Hauschild A, Grpb JJ, ChiarionSileni V, Lebbe C, Mandala M, Millward M, Arance A, Bondarenko I, Haanen JB, Hansson J, Utikal F, Ferraresi V, Kovalenko N, Mohr P, Probachai V, Schadendorf D, Nathan P, Robert C, Robas A, DeMarini DJ, Irani JG, Swann S, Legos JJ, Jin F, Mookerjee B and Flaherty K: Dabrafenib and trametinib versus dabrafenib and placebo for Val600 BRAF-mutant melanoma: A multicentre, double-blind, phase 3 randomised controlled trial. Lancet 386: 444-451, 2015.

24 Long GV, Weber JS, Infante JR, Kim KB, Daud A, Gonzales R, Sosman JA; Mamid O, Schuchter L, Cebon J, Kefford RF, Lawrence D, Kudchadkar R, Burris HA 3rd, Falchook GS, Algazi A, Lewis K, Puzanov I, Ibrahim N, Sun P, Cunningham E, Kline AS, Del Buono H, McDoell DO and Flaherty KT: Overall survival and durable responses in patients with $B R A F$ V600-mutant metastatic melanoma receiving dabrafenib combined with trametinib. J Clin Oncol 34: 871-878, 2016.

Received October 2, 2018

Revised October 14, 2018

Accepted October 16, 2018 